Société d'histoire de la révolution de 1848 et des

révolutions du XIXe siècle

$63 \mid 2021$

Puissances de la Commune

Yannick RIPA, Histoire féminine de la France. De la Révolution à la loi Veil

Paris, Belin, 2020

Emmanuelle Retaillaud

\author{
CpenEdition \\ Journals \\ Édition électronique \\ URL : https://journals.openedition.org/rh19/8178 \\ DOI : $10.4000 /$ rh 19.8178 \\ ISSN : $1777-5329$ \\ Éditeur \\ La Société de 1848
}

Édition imprimée

Date de publication : 1 décembre 2021

Pagination : 262-263

ISSN : 1265-1354

Référence électronique

Emmanuelle Retaillaud, «Yannick RIPA, Histoire féminine de la France. De la Révolution à la loi Veil », Revue d'histoire du XIXe siècle [En ligne], 63 | 2021, mis en ligne le 01 janvier 2022, consulté le 21 février 2022. URL : http://journals.openedition.org/rh19/8178 ; DOl : https://doi.org/10.4000/rh19.8178

Ce document a été généré automatiquement le 21 février 2022.

Tous droits réservés 


\title{
Yannick RIPA, Histoire féminine de la France. De la Révolution à la loi Veil
}

Paris, Belin, 2020

\author{
Emmanuelle Retaillaud
}

\section{RÉFÉRENCE}

Yannick RIPA, Histoire féminine de la France. De la Révolution à la loi Veil, Paris, Belin, 2020, 765 pages, 41 euros.

1 En entreprenant cette Histoire féminine de la France, Yannick Ripa a voulu, dit-elle, contrebalancer «un certain effacement de l'histoire des femmes, conséquence inattendue de l'impact de celle du genre » - autrement dit, la bascule de l'étude des individu.e.s concrèt.es à celle des constructions symboliques et des représentations, qui serait devenue la tendance dominante de l'historiographie récente. Si les deux dimensions sont bien sûr inextricablement liées, il est clair que privilégier l'une ou l'autre de ces approches ne produit pas le même type d'histoire, et que c'est bien à un retour des actrices - et sur leur pourtour, des acteurs - que nous assistons ici, dans leur dimension concrète et «située ». Pour autant, l'historienne n'entend pas revenir à une histoire "des femmes » telle qu'elle l'a elle-même pratiquée dans son excellent petit manuel de 1999 Les femmes actrices de l'histoire, France 1789-1945 (chez SEDES puis chez Armand Colin), ou telle qu'on la trouve chez Christine Bard, avec Les Femmes dans la société française au $20^{e}$ siècle (Armand Colin, 2001) ou chez Michelle Zancarini-Fournel, avec l'Histoire des femmes en France XIXe-XXe siècle (PUR, 2008). Si l'adjectif « féminine » fait discrètement écho à l'histoire mondiale (p. Boucheron) ou populaire (M. ZancariniFournel) de la France, il entend surtout se situer à la croisée d'une histoire concrète et d'une histoire des constructions du "féminin », qui passe aussi, inévitablement, par une histoire du féminisme.

2 Ce parti-pris débouche sur un livre d'une grande richesse, à la fois accessible, agréable à lire et à consulter - grâce, notamment à une riche iconographie et à une mise en page 
soignée -, mais sans concession à la vulgate sur le fond. Démarrant en 1789, s'achevant, par choix assumé, en 1975, il est résolument centré sur une histoire contemporaine initiée par la Révolution française et par le Code civil de 1804. Remarquons à ce propos que, si les scansions principales demeurent presque inévitablement celles de l'histoire politique et institutionnelle - donc masculine -, l'intérêt de cette approche "féminine " est de produire un "autre vécu de l'événementiel» puisque "le temps féminin contrarie la chronologie officielle». Ce ne sont donc pas les régimes, les guerres, les révolutions qui structurent au premier chef l'architecture du propos, même si leur dimension genrée est longuement analysée, mais plutôt les focales d'une histoire sociale ou anthropologique qui scrute au plus précis les éléments structurants du vécu et des normes des destins féminins, corps, éducation, vêtement, sexualité, mariage, maternité.

3 Abordés, donc, sur le versant des tendances de longue durée, ces deux siècles n'en sont pas moins caractérisés par l'accélération continue de l'histoire, sous l'effet de la révolution industrielle, du progrès technique, de l'avènement de la modernité esthétique ou politique, si bien que c'est un tableau évolutif et dynamique qui se dégage de l'ensemble, après un premier XIX ${ }^{e}$ siècle parfois désespérant d'immobilisme. Mais là encore, l'approche à la charnière de l'histoire sociale et de l'histoire des normes ou des discours permet d'éviter subtilement tout simplisme quant aux effets systémiques du "patriarcat » ou de la «domination masculine", dont les lois et les textes donnent à voir la face la plus monolithique et la plus rigide. À propos des travailleuses commerçantes, paysannes, ouvrières... -, Yannick Ripa remarque ainsi : « il ne faudrait pas minimiser [les] restrictions de leurs droits. Cependant, ces bastions masculins n'impliquent pas [...] que les femmes ne se consacrent qu'à la sphère privée. En milieu rural comme urbain, d'aucunes ne respectent nullement cette imaginaire frontière entre les deux sphères, et nul ne l'ignore ni ne s'en émeut » (p. 257). De même peut-elle remarquer à propos des privilégiées: "corsetées au propre comme au figuré, elles disposent d'une agency restreinte mais au regard de la vie des femmes, la leur est douce ». Tenir un juste équilibre entre l'étude - et implicitement, la dénonciation - de la hiérarchisation inégalitaires des sexes et celle de la complexité des pratiques sociales n'est pas un des moindres mérites du livre.

4 Il aboutit, de fait, à la mise en majesté d'un long XIX siècle, de 1804 à 1914, en traitant de manière plus rapide les bouleversements pourtant décisifs du siècle suivant : peutêtre parce qu'ils ont été jugés mieux connus, peut-être parce que l'auteure a privilégié, consciemment ou non, ses propres terrains de recherche. Si l'on souscrit pleinement aux remarques de l'introduction relatives à la difficulté de définir une date-butoir, on ne peut s'empêcher de penser qu'un léger rééquilibrage aurait été possible, notamment en réduisant la part tout de même exorbitante consacrée à la guerre de 1870 et à la Commune - 91 pages pour à peine une année peut-être pas si décisive que ça dans l'histoire des femmes, quand la Première Guerre mondiale n'en mobilise que 36 et la Seconde 54 - tout en poussant l'analyse jusqu'au début des années 1980, quand les acquis du féminisme semblent à peu près digérés et l'égalité théoriquement réalisée le ministère Roudy (1981-1986), le remboursement de l'IVG (1982), la figure ambiguë de la «femme libérée » ou de la «célibattante » pouvaient offrir des points d'appui factuels à la délimitation de cette phase. L'absence de conclusion formelle, un peu regrettable, témoigne de cette difficulté à clore, alors que le très contemporain permet d'ores et déjà de discerner, à partir des années 2010, une nouvelle phase de cette histoire "féminine», produite par la déstabilisation queer des normes de sexe et de 
genre, mais aussi à l'assombrissement de la sensibilité sociale qui, après des décennies de progrès apparents et d'égalisation des conditions, se montre désormais plus attentive aux limites, aux incomplétudes ou aux impasses des "progrès » du féminisme, autour des enjeux de violences sexuelles ou de "plafond de verre» socioéconomique, eux-mêmes filtrés par le concept d'intersectionnalité.

5 Compte tenu de l'ampleur du sujet et de la période étudiée, l'ouvrage est inévitablement incomplet, notamment dans le traitement un peu rapide des réalités coloniales et post-coloniales ou dans l'escamotage revendiqué des "grandes figures » au profit des groupes, des anonymes ou des "subalternes». Il n'en représente pas moins une somme aussi érudite qu'élégante et offre, à l'histoire savante, une passerelle idéale vers la bibliothèque de tous les citoyen.nes éclairé.es. 